\title{
Prevalence and spatial distribution of bovine brucellosis in San Luis and La Pampa, Argentina
}

\author{
M. N. Aznar ${ }^{1,2^{*}}$, F. J. Linares ${ }^{3}$, B. Cosentino ${ }^{3}$, A. Sago ${ }^{4}$, L. La Sala ${ }^{5}$, E. León ${ }^{1}$, S. Duffy ${ }^{6}$ and A. Perez ${ }^{7}$
}

\begin{abstract}
Background: Bovine brucellosis (BB) is a zoonotic disease caused by Brucella abortus. BB is endemic in Argentina, where vaccination with Brucella abortus strain 19 is compulsory for 3-to-8 month-old heifers. The objectives of this study were to quantify the prevalence of $\mathrm{BB}$ and to identify factors associated with its occurrence, along with the spatial distribution of the disease, in the provinces of La Pampa and San Luis. A two-stage random sampling design was used to sample 8,965 cows (3,513 in La Pampa and 5,452 in San Luis) from 451 farms (187 in La Pampa and 264 in San Luis).

Results: Cow and herd prevalence were $1.8 \%$ (95 \% Cl: 1.3-2.2; $n=157)$ and $19.7 \%$ (95 \% Cl: 17.0-22.4; $n=89$ ), respectively. Both cow-level and herd-level prevalence in La Pampa (2.4 and $26.0 \%$, respectively) were significantly higher than in San Luis (1.4 and $15.5 \%$, respectively). There were not differences between the proportions of reactive cattle compared to that obtained in a survey conducted in 2005. However, herd prevalence in La Pampa was significantly $(P<0.05)$ higher compared to that study. Disease was found to be spatially clustered in west La Pampa. The lower the bovine density and the calf/cow ratio, the higher odds of belonging to the cluster.

Conclusions: The increase of farm prevalence in the last five years suggests that the disease is spreading and that control measures should be applied in the region.

The cluster of infected farms was located in the west region of La Pampa. There, farms have lower animal densities and smaller cow/calf indices compared to the rest of the province. Although western La Pampa has more infected herds, within-farm prevalence was not higher, which suggests that the control program has been relatively successful in controlling the disease at the farm level, and/or that low animal density inherently results in low disease prevalence. Our results provide baseline information on the epidemiology of $\mathrm{BB}$ and its potential pattern of transmission in Argentina, which will ultimately help to improve BB control programs in the country.
\end{abstract}

Keywords: Bovine brucellosis, Prevalence, Spatial analysis, Argentina

\section{Background}

Brucellosis is considered one of the most widespread zoonotic diseases worldwide [1]. The disease is caused by various bacteria belonging to the genus Brucella, which affects many mammalian species, including cattle, goats, pigs, and sheep. Bovine brucellosis (BB), which is predominantly caused by Brucella abortus, is usually detected in pregnant females that abort [2], which may

\footnotetext{
* Correspondence: aznar.maria@inta.gob.ar

'Área de Patología, Epidemiología y Medicina Preventiva. Instituto de Patobiología. ClCVyA, Instituto Nacional de Tecnología Agropecuaria, Hurlingham PC 1688, Argentina

${ }^{2}$ Faculty of Veterinary Medicine, Department of Infectious and Parasitic Diseases, Research Unit of Epidemiology and Risk Analysis Applied to Veterinary Sciences (UREAR), University of Liege, Liege PC 4000, Belgium Full list of author information is available at the end of the article
}

develop life-long infection. BB reduces fertility and milk production and may be transmitted to humans by direct or indirect contact with infected animals [1]. Because prevalence in animals influences disease incidence in humans [3], control in animal populations is important to improve the productive capability of herds and to protect the human population from infection.

BB is endemic in Argentina. In 1998, the Argentine dairy industry launched an incentive program for BBfree herds, which encouraged milk producers to improve the sanitary status of their herds by reducing the prevalence [4]. Currently, the disease is more frequently controlled in dairies compared to beef farms [5], and 5,870 dairy farms (53\% of the total dairy farms) have been officially certified as BB-free (SENASA, unpublished data). 
The Argentine National Bovine Brucellosis Control Program [6] establishes the compulsory vaccination of 3-to-8 month-old heifers with Brucella abortus strain 19. The province of Tierra del Fuego, in southern Patagonia, is BB-free and vaccination is forbidden there [7].

Quantitative knowledge on the disease prevalence and spatial distribution is prerequisite for designing and assessing the evolution of disease control programs [8].

The economic role of cattle breeding, in La Pampa and San Luis provinces (Fig. 1), is prominent, particularly for beef cattle. Approximately $29-35 \%$ of the females and $1 \%$ of the bulls produced in the region are shipped into premises located in other regions of Argentina (SENASA, unpublished data). Regarding La Pampa, this province includes three different productive areas referred to as northeast, central (Caldenal), and west [9]. The west region is mostly (98\%) covered with xerophytic native forest and grassland. It is an area with big extensive breeding farms and comprised mainly of cow-calf operations with a low calf/cow index. Similarly, $88 \%$ of the central area is comprised of native forest and grassland, but includes a combination of both cow-calf and fattening operations with a higher calf/cow index. In the northeastern area, only $25 \%$ of the land is covered by forests and grassland, and calf breeding/fattening activities are combined in the same operations or conducted separately with the highest calf/cow index.

Knowledge on the epidemiological status of $\mathrm{BB}$ in the region is scarce. In 2005, SENASA conducted a survey in La Pampa and San Luis provinces to estimate the prevalence of the disease in beef cattle, and reported a cow-level prevalence of 2.6 and $1.8 \%$, and a herd-level prevalence of 11.0 and $9.0 \%$, respectively (SENASA, unpublished data). However, no structured assessment of the epidemiological situation of $\mathrm{BB}$ in the region has been conducted since then.

The objectives of the study here were 1 ) to estimate the $\mathrm{BB}$ prevalence at farm and province levels, and 2) to identify factors associated with the occurrence of disease and their association with spatial clustering of cases. Results will help to characterize the epidemiology of

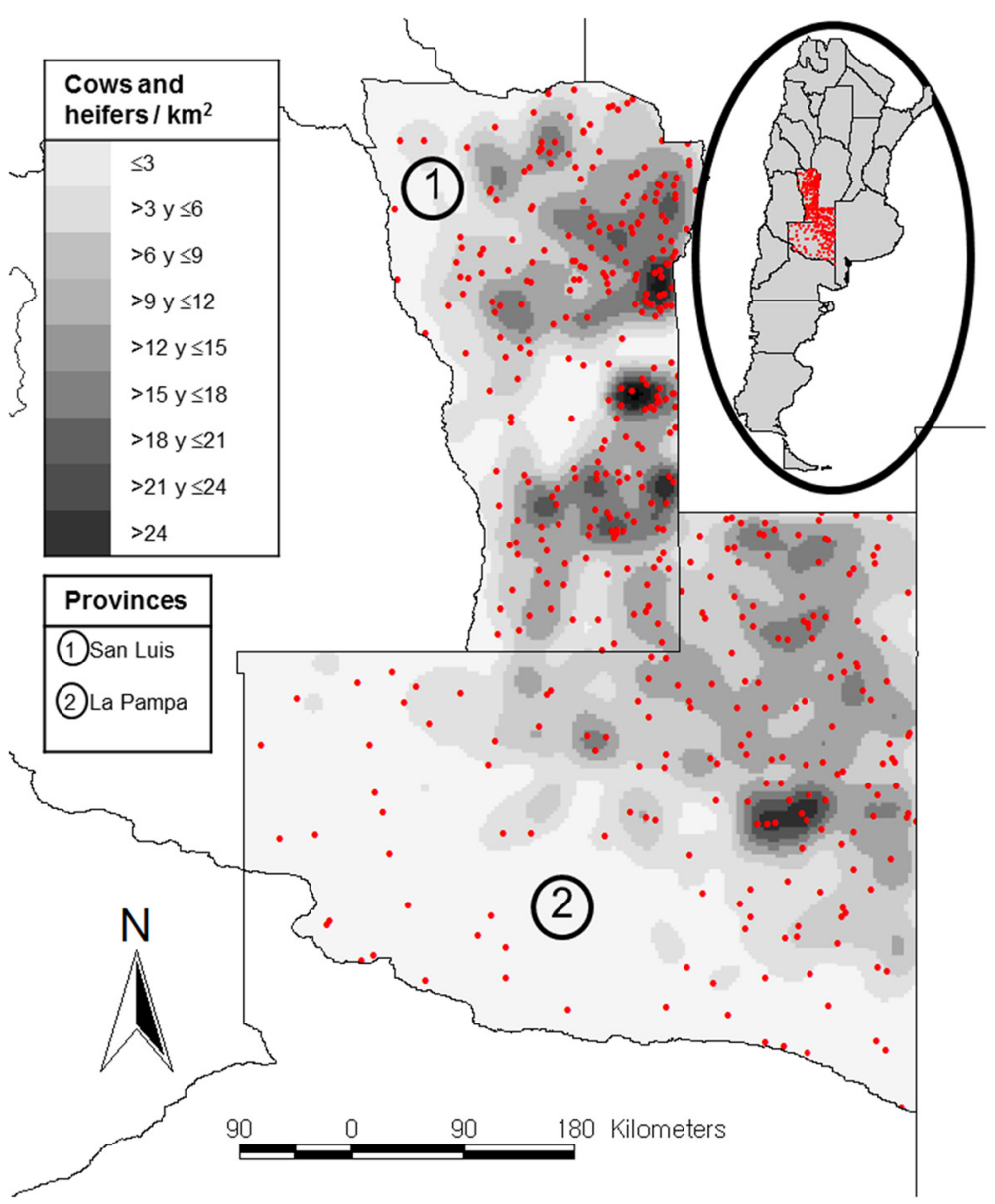

Fig. 1 Map of Argentina (circle) showing the studied area (red dots), and a detail of La Pampa and San Luis provinces showing a kernel density of cows and heifers (tones of grey) and the geographic distribution of the 451 sampled farms (red dots) 
the disease and, ultimately, to evaluate and improve the effectiveness of $\mathrm{BB}$ control programs in the region.

\section{Methods}

La Pampa has a cattle population of 2.7 million distributed in 8,000 farms, whereas San Luis has 1.4 million head in 6,000 farms (SENASA 2013, unpublished data). A two-stage random-sampling design was used to estimate the proportion of infected cows. In the first stage, farms (primary sampling units) were selected with a probability of selection proportional to the number of cattle in the farm. In the second stage, cattle (secondary sampling units) were randomly selected from each farm.

The number of farms to be selected in the region under study (n) was calculated using the following formula:

$$
\mathrm{n}=\frac{\mathrm{p} \times(1-\mathrm{p}) \times \mathrm{z}^{2} \times[\mathrm{ROH} \times(\mathrm{b}-1)+1]}{\mathrm{e}^{2} \times \mathrm{b}}
$$

where $\mathrm{p}$ is the expected proportion of cows reactive to brucellosis, $\mathrm{z}$ is the level of confidence, $\mathrm{ROH}$ is the rate of homogeneity, $\mathrm{b}$ is the number of animals selected per farm (may be variable: the fewer individuals per farm the greater the number of farms to be selected) and e is the acceptable absolute error. Our assumptions were: expected proportion of cows reactive to brucellosis: $2.6 \%$ for La Pampa and $1.8 \%$ for San Luis (based on the SENASA survey 2005), level of confidence: $95 \%$; relative error: $30 \%$; rate of homogeneity: low.

The result was that a minimum of 415 farms were needed.

A total of 19 cows was chosen per farm taking into account that it is the number for detecting the disease if its prevalence is $\geq 0.15$ and that it was also a feasible number for operative reasons. So, a total of 7,885 cows was required.

In farms where the population size was $<19$, the entire population was sampled. In some farms more than 19 animals were sampled to compensate such reduction and reach the total number of samples targeted for the region. The software ProMesa 1.3 was used in sample size calculations [10].

Data on cattle population, farm characteristics (location and size) and cattle movements during 2009 in the region under study were obtained from the SENASA Integrated Sanitary Management System (Sistema Integrado de Gestión de Sanidad Animal - "SIGSA") for each sampled farm.

Serum samples were obtained by SENASA local veterinarians during 2010.

\section{Ethical approval}

The INTA CICUAE committee ruled that no formal ethics approval was required in this case, in which the sampling was part of a SENASA surveillance activity. In all cases, informed verbal consent was obtained from the cattle owners.

\section{Serology}

The buffered plate agglutination test (BPAT) was used as screening test (sensitivity $[\mathrm{Se}]=95.4 \%$; specificity $[\mathrm{Sp}]=97.7 \%)$. Positive samples were confirmed using the 2- mercaptoethanol (2ME; Se=88.4\%: Sp=91.5\%) and the serum agglutination tests (SAT; Se $=75.9 \%$ : $\mathrm{Sp}=95.7 \%$ ) [11], as stated by the SENASA Resolution 438/2006 [12].

Those animals that tested positive for BPAT, 2ME, and SAT tests were classified as positive, and as negative otherwise. According to the Argentine legislation [6], premises with at least one reactive animal were defined as BB-infected.

\section{Statistical analysis}

Prevalence was computed for each province (San Luis and La Pampa). Results were compared with those obtained in the SENASA 2005 survey. Prevalence values were compared between provinces and years using the Fisher's exact test. Statistical analyses were performed using Statistix 8.0 [13].

The association between various independent variables and outcomes (infected/not infected farm; count of reactive cows per farm; located inside/outside a high prevalence cluster) were evaluated.

A first generalized linear model (GLM; logistic) was built to assess association between the dependent variable "infected/not infected farm" and independent variables, which were categorized as dichotomous using two different cut-off values: a) the median considering only the sampled farms; b) the median considering the total beef farms population in both provinces. The list of independent variables and cut-off values are presented in Table 1. A second GLM (Poisson) was carried out for evaluating the association between the same variables and cut-off values used for the first model and the count of reactive cows per farm as dependent variable.

Clustering of BB-infected farms was assessed using two methods suggested for outbreak investigations [14]. First, the Cuzick- Edwards' test [15] was used to detect any overall, globally clustered distribution of cases at the farm level using the ClusterSeer 2.5.1 software [16]. The test statistic $\mathrm{T} k$, which represents the number of cases (i.e. farms) that are nearest to each individual case, was calculated. Here, the first ten orders $(k=1-10)$ of nearest-neighbors measurements were examined and significance was computed using 999 Monte Carlo iterations. After the initial detection of a global clustering of positive farms, further analyses were done to locate and characterize the 
Table 1 Cut-off values for categorization of independent variables: (A) median of sampled farms; (B) median of the total beef farms population in both provinces

\begin{tabular}{lll}
\hline Independent variable & Cut-off (A) & Cut-off (B) \\
\hline Farm surface (Has) & 500 & 300 \\
Bovine density (animals/Has) & 0.5 & 0.25 \\
Calf/cow ratio & 0.5 & 0.36 \\
Number of cows per farm & 600 & 85 \\
Number of heifers per farm & 50 & 23 \\
$\begin{array}{l}\text { Number of cows and heifers shipped to } \\
\text { and from the farm during the previous year }\end{array}$ & 50 & 25 \\
$\begin{array}{l}\text { Number of farms shipping cattle to/from } \\
\text { another farm during the previous year }\end{array}$ & 10 & 15 \\
\hline
\end{tabular}

cluster/s using the spatial scan statistic [17]. A Bernoulli model was implemented to identify clusters of positive farms, followed by a Normal model to detect clustering of farms with high prevalence. Cluster analyses were done using the SatScan software [18].

Following the spatial analysis and identification/location of clusters, herds were categorized as located within/outside a cluster. Then, a third GLM was built to investigate association between the variable of interest (located inside/outside a cluster) and the independent variables with the same cut- off mentioned above (Table 1).

Model building began by a univariate analysis of each variable. Variables having a significant univariate test at an initial p-value cut-off point of 0.20 were included in a multivariate model. Confounding was considered if removing single variables from the multivariable model changed any of the parameter estimates by $20 \%$ or more compared to the full model [19]. At the end of the process, the model contained only significant independent variables without confounders. To be included in the models, independent variables were required to be significant under both cut-off scenarios considered (sampled farms and population-level medians).

The associations between the outcome and independent variables were quantified by the estimation of the odds ratios (OR) and their $95 \%$ confidence intervals (95\% CI), for the two cut-off levels. Final model selection was based on the Deviance Information Criterion (DIC).

The sampled farms were mapped in ArcGIS 9.3 software [20]. The spatial distribution of cows and heifers was mapped using a kernel density function [21] of the same software (Fig. 1).

\section{Results and discussion}

In $70 \%$ of the farms, the originally 19 targeted samples were obtained, whereas in the remaining $30 \%$ the number of samples varied between 10 and 25, depending on the number of cows per farm. The geographic distribution of the sampled farms, overlapping the density of cows and heifers in each province (expressed as number of animals per $\mathrm{km}^{2}$ ) is shown in Fig. 1 .

Almost $20 \%$ of the farms were infected, showing not only a high frequency but also a high dispersion of the infection, with the majority of the infected farms having a proportion of reactive cows lower than $10 \%$. Intra-

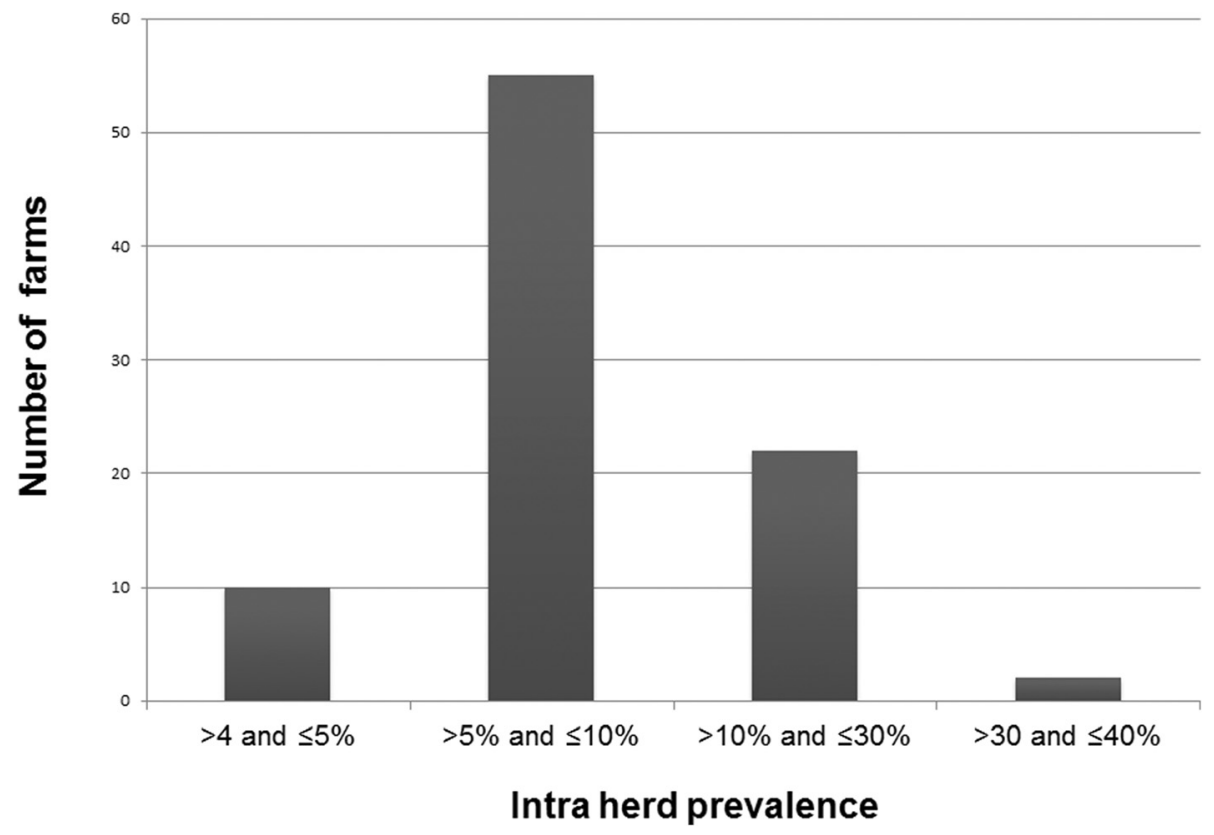

Fig. 2 Frequency distribution of the infected farms $(n=89)$ by intra-herd prevalence 
Table 2 Province-level number of samples, positive results and BB prevalence for cattle and farms, with their confidence interval

\begin{tabular}{|c|c|c|c|c|c|c|}
\hline \multirow[t]{2}{*}{ Province } & \multicolumn{3}{|l|}{ Cattle } & \multicolumn{3}{|c|}{ Farms } \\
\hline & Total & Reactive & Prevalence (\%) & Total & Positive & Prevalence (\%) \\
\hline La Pampa & 3,513 & 83 & $2.4(1.6-3.2)^{a}$ & 187 & 48 & $26.0(20.0-31.3)^{a}$ \\
\hline San Luis & 5,452 & 74 & $1.4(0.9-1.8)^{b}$ & 264 & 41 & $15.5(11.8-19.3)^{k}$ \\
\hline Total & 8,965 & 157 & $1.8(1.3-2.2)$ & 451 & 89 & $19.7(17.0-22.4)$ \\
\hline
\end{tabular}

Prevalence values with different letters mean statistic differences $(P<0.05)$

${ }^{a}$ is the prevalence for La Pampa and ${ }^{b}$ is for San Luis

farm prevalence ranged from 4.3 to $40 \%$, with a median prevalence of $5.3 \%$ (Fig. 2).

The prevalence of reactive cows and infected farms were higher in La Pampa than in San Luis $(P<0.05$; Table 2). However, the observed differences were not relevant in terms of control of the disease and may not justify the application of differential sanitary strategies in these provinces.

Compared with the SENASA 2005 survey results, no significant differences were observed in the proportion of reactive cattle ( $P>0.05$ for both provinces).
However, at farm level the prevalence was higher in both provinces, differences being significant only for La Pampa $(P<0.05)$.

None of independent variables assessed here were significantly associated with the farm-level infection status, nor with the number of reactive cows per farm.

A significant global clustering (Simes $P<0.05$ ) of positive herds was detected using the Cuzick and Edwards' test. Clustering of infected herds was detected at $k=1$ ( T $k=26, \mathrm{E}[\mathrm{T} k]=17.4, P<0.05)$. This result is consistent with patterns of local disease transmission.

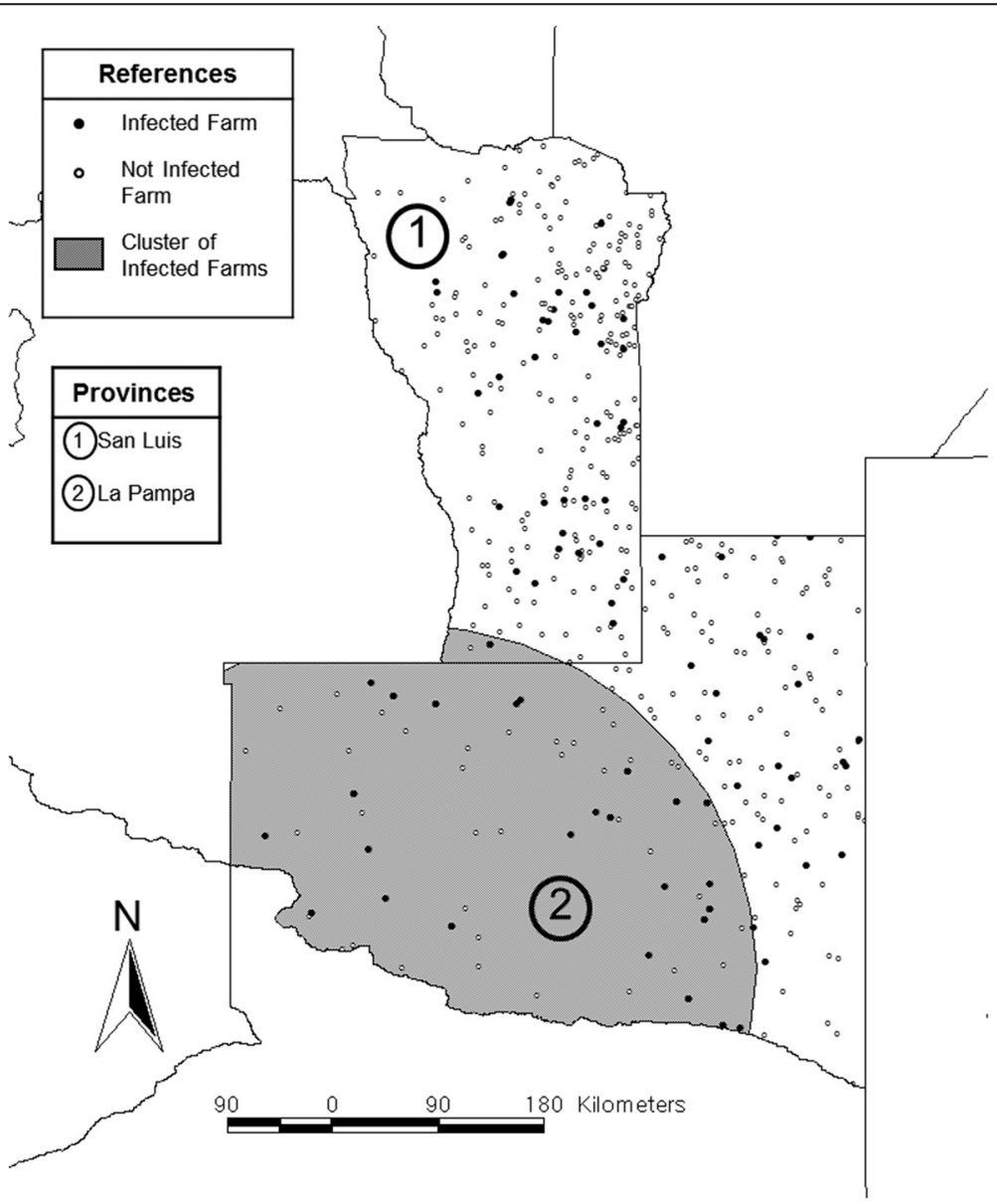

Fig. 3 Geographic distribution of the uninfected (white dots) and infected (black dots) farms. The shaded area shows the cluster of infected farms detected by the Bernoulli model 
Using the Bernoulli model, a spatial cluster of infected farms was detected in La Pampa (38.38 S, $66.92 \mathrm{~W}$; radius $=250 \mathrm{~km} ; P<0.05$ ) (Fig. 3 ), where the risk for infection was nearly $2.6(\mathrm{RR}=2.58 ; P<0.05)$ times higher in farms located inside the cluster than in those located elsewhere.

Contrarily, the Normal model was not significant, suggesting the absence of clusters that included farms with high within-farm prevalence.

The multivariate analysis showed that lower bovine densities and lower calf/cow ratio are associated with higher odds of being inside a disease cluster $(P<0.05)$, regardless the cut-off level used for categorization. Farm surface was significantly associated only when modeled as categorical variable using as cut-off value the median of the sampled farms (Table 3). Therefore, this variable was not included in the final model, which only includes bovine density and calf/cow ratio.

\section{Conclusions}

The increase of farm prevalence in the last five years suggests that the disease is spreading and that control measures should be applied in the region.

The cluster of infected farms was located in the west region of La Pampa described. There, farms have lower animal densities and smaller cow/calf indices compared to the rest of the province. Although no significant association was found between the risk of being in the cluster and farm surface when using both cut-off values for this variable (Table 3), results suggest an increased risk for being in the cluster in farms larger than 500 has. Those farms are managed more extensively and thus they are less productive, which likely correlates with infrequent veterinary control and poorer sanitary conditions of the herds, compared with smaller farms. Although western La Pampa has more infected herds, within-farm prevalence was not higher. This finding suggests that the control program has been relatively successful in controlling the disease at the farm level, and/or that low animal density inherently results in low disease prevalence. In any case, it is probable that within-farm prevalence was not sufficiently reduced

Table 3 Summary of logistic regression model showing the variables with significant association with the odds of being inside the cluster. Results are presented for both cut-off values used for independent variables

\begin{tabular}{|c|c|c|c|c|}
\hline Variables & Cut-off (A) & OR $(95 \%$ Cl) & Cut-off (B) & OR $(95 \%$ Cl) \\
\hline Surface & $<300$ ha & $5.34(0.72-39.69)$ & $<500$ & $12.47(1.65-94.34)$ \\
\hline $\begin{array}{l}\text { Bovine } \\
\text { density }\end{array}$ & $\begin{array}{l}\geq 0.24 \\
\text { animals/ha }\end{array}$ & $8.23(4.19-16.19)$ & $\begin{array}{l}\geq 0.5 \\
\text { animals/ha }\end{array}$ & $4.99(1.89-3.17)$ \\
\hline $\begin{array}{l}\text { Calf/cow } \\
\text { index }\end{array}$ & $\begin{array}{l}\geq 0.36 \\
\text { animals/ha }\end{array}$ & $2.63(1.45-4.77)$ & $\begin{array}{l}\geq 0.5 \\
\text { animals/ha }\end{array}$ & $3.31(1.81-6.04)$ \\
\hline
\end{tabular}

so as to reduce the number of infected farms in the region.

Our results provide baseline information on the epidemiology of $\mathrm{BB}$ and its potential pattern of transmission in Argentina, which will ultimately help to improve BB control programs in the country.

\section{Abbreviations}

BB: Bovine brucellosis; BPAT: Buffered plate agglutination test; Cl: Confidence interval; DIC: Deviance information criterion; GLM: Generalized liner model; OR: Odds ratio; RR: Relative risk; SAT: Serum agglutination test; SENASA: National Service for Agrifood Health and Quality; SIGSA: Sistema Integrado de Gestión de Sanidad Animal; 2ME: 2-mercaproethanol.

\section{Competing interests}

The authors declare that they have no competing interests.

\section{Authors' contributions}

BAC participated in the conception and design of the study and AS performed the field work. MNA, AMP, FJL and LLS analyzed the data and wrote the manuscript. SD and EAL contributed to the analysis and helped in the manuscript discussion. All authors have read and approved the final version of the manuscript.

\section{Acknowledgments}

This project was funded in part by the University of Minnesota MnDrive initiative. We acknowledge the local veterinary staff from the Regional Center of La Pampa-San Luis (SENASA) and the Regional Laboratory of La Pampa. We also thank Dr. Cutullé, from INTA, for revising the manuscript.

\section{Author details}

'Área de Patología, Epidemiología y Medicina Preventiva. Instituto de Patobiología. CICVyA, Instituto Nacional de Tecnología Agropecuaria, Hurlingham PC 1688, Argentina. ${ }^{2}$ Faculty of Veterinary Medicine, Department of Infectious and Parasitic Diseases, Research Unit of Epidemiology and Risk Analysis Applied to Veterinary Sciences (UREAR), University of Liege, Liege PC 4000, Belgium. ${ }^{3}$ Dirección de Epidemiología y Análisis de Riesgo, Dirección Nacional de Sanidad Animal, Servicio Nacional de Sanidad y Calidad Agroalimentaria, Ciudad Autónoma de, Buenos Aires PC 1063, Argentina. ${ }^{4}$ Centro Regional La Pampa-San Luis, Servicio Nacional de Sanidad y Calidad Agroalimentaria, La Pampa PC 6300, Argentina. ${ }^{5}$ Cátedra de Parasitología Cínica. Departamento de Biología, Bioquímica y Farmacia, Universidad Nacional del Sur, Bahía Blanca PC 8000, Argentina. ${ }^{6}$ Centro de Estudios Cuantitativos en Sanidad Animal, Facultad de Ciencias Veterinarias. Universidad Nacional de Rosario, Casilda PC 2170, Argentina. ${ }^{7}$ Department of Veterinary Population Medicine, College of Veterinary Medicine. University of Minnesota, Minnessota, MN 55113, USA.

Received: 6 January 2015 Accepted: 6 August 2015

Published online: 15 August 2015

\section{References}

1. World Health Organization (WHO), 2006. The control of neglected diseases. A route to poverty alleviation. Report of a Joint WHO/DFID-AHP meeting with the participation of FAO and OIE. [http://www.who.int/zoonoses/Report_ Sept06.pdf]

2. England T, Kelly L, Jones RD, MacMillan A, Wooldridge M. A simulation model of brucellosis spread in British cattle under several testing regimes. Prev Vet Med. 2004;63:63-73.

3. Saegerman C, Berkvens D, Godfroid DJ, Walravens K. Bovine brucellosis. In: Lavoisier, editor. Infectious and parasitic disease of livestock. France: Editions Tec et Doc; 2010. p. 971-1001.

4. Samartino LE. Brucellosis in Argentina. Vet Microbiol. 2002;90:71-80.

5. Aznar MN, Samartino LE, Humblet M-F, Saegerman C. Bovine brucellosis in Argentina and bordering countries: update. Transbound Emerg Dis. 2014;61:121-33.

6. SENASA, 2002. Resolución N¹50. Restablece el Plan de Control y Erradicación de la Brucelosis Bovina. [http://www.senasa.gov.ar/contenido.php?to=n\&in= 1077\&io=3002] 
7. SENASA, 2011. Resolución N¹00. Se declara a la Provincia de Tierra del Fuego, Antártida e Islas del Atlántico Sur, como "Zona Libre de Brucelosis y Tuberculosis bovina". [http://www.senasa.gov.ar/contenido.php?to=n\&in= 1501\&io=15574]

8. de la Sota M, Bagnat E, Cosentino B, Nicola A. Aproximación a la determinación de la prevalencia nacional de la brucelosis bovina. Rev Col Vet Prov Bs As. 2005;11:31-5.

9. CREA, 2010. Análisis del sector agropecuario en relación a la economía provincial. [http://www.aaglp.org.ar/novedades/analisis-sector-agropecuario-la-pampajunio2010.pdf]

10. León E, Duffy S: ProMESA (Programa de Muestreo Estadístico en Sanidad Animal). In: Anales $39^{\circ}$ Jornadas Argentinas de Informática y Congreso Argentino de Agroinformática: 2010; 2010: 807-817

11. Gall D, Nielsen K. Serological diagnosis of bovine brucellosis: a review of test performance and cost comparison. Rev sci tech Off int Epiz. 2004;23:989-1002

12. SENASA, 2006. Resolución N438. Se adopta el Sistema de Diagnóstico Serológico para el Programa de Control y Erradicación de la Brucelosis. [http://www.senasa.gov.ar/contenido.php?to=n\&in=1029\&io=3630]

13. Analytical Software: Statistix 8 for Windows. Tallahassee FL 32317, USA. 2003.

14. Ward MP, Carpenter TE. Techniques for analysis of disease clustering in space and in time in veterinary epidemiology. Prev Vet Med. 2000;45:257-84

15. Cuzick J, Edwards R. Spatial clustering for inhomogeneous populations. J R Statist Soc B. 1990;52:73-104.

16. Jacquez GM. Stat! statistical software for the clustering of health events. Ann Arbor, Ml: BioMedware; 1994.

17. Kulldorff M, Nagarwalla N. Spatial disease clusters: Detection and inference. Stat Med. 1995;14:799-810.

18. Kulldorff M, Rand K, Gherman G, Williams G, DeFrancesco D. SaTScan version 2.1.3. Software for the spatial and space-time scan statistics. Bethesda, MD: National Cancer Institute; 1998.

19. Hosmer DW, Lemeshow S. Applied logistic regression. New York: Wiley; 2000

20. ESRI. ArcGIS Desktop: Release 9.3. 380 New York Street, Redlands, CA 92373-8100. USA: ESRI; 2009.

21. Silverman BW. Density estimation for statistics and data analysis. London: Chapman and Hall; 1986.

\section{Submit your next manuscript to BioMed Central and take full advantage of:}

- Convenient online submission

- Thorough peer review

- No space constraints or color figure charges

- Immediate publication on acceptance

- Inclusion in PubMed, CAS, Scopus and Google Scholar

- Research which is freely available for redistribution 